\title{
Responses of Flavonoids, Phenolics, and Antioxidant Activity in Rice Seedlings between Japonica and Indica Subtypes to Chilling Stress
}

\author{
Ramin Rayee ${ }^{1,2, a}$, Tran Dang Xuan ${ }^{1, b *}$, Hoang-Dung Tran ${ }^{3, c}$, \\ Naqib Ahmad Fakoori ${ }^{1, d}$, Tran Dang Khanh ${ }^{4, e}$, Tran Dang Dat ${ }^{5, f}$ \\ ${ }^{1}$ Graduate School for International Development and Cooperation (IDEC), Hiroshima University, \\ Higashi-Hiroshima, Japan \\ ${ }^{2}$ Agronomy Department, Faculty of Agriculture, Takhar University, Takhar, Afghanistan \\ ${ }^{3}$ Agricultural Genetics Institute, Hanoi City, Vietnam \\ ${ }^{4}$ Department of Biotechnology, NTT Institute of Hi-Technology, Nguyen-Tat-Thanh University, \\ Ho Chi Minh City, Vietnam \\ ${ }^{5}$ Khai Xuan International Co. Ltd., Ha Dong District, Duong Noi Ward, LK20A-20B, Khai Xuan \\ Building, Hanoi 152611, Vietnam \\ ar.rayee12@yahoo.com, b'tdxuan@hiroshima-u.ac.jp, 'thdung@ntt.edu.vn, \\ dnaqibullah_fakory2004@yahoo.com, ’tdkhanh@vaas.vn, fkhaixuan.study@gmail.com
}

Keywords: Total phenolic content; total flavonoid content; antioxidant activity; chilling stress; rice; phenolic acid; bound form; free form

\begin{abstract}
Chilling is one of the major abiotic stress which limites yield and quality of many crops. The seedlings of rice varieties namely Koshihikari (Japonica subtype) chilling tolerant, and the susceptible NMR2 (Indica subtype) were treated at $25 / 15^{\circ} \mathrm{C}$ and $5 / 4{ }^{\circ} \mathrm{C}$ day/night to determine the growth parameters, phenolic contents, and antioxidant activity. It was found that in all treatments, the growth of MNR2 including root and shoot lengths, and leaf and root weights were inhibited at greater levels than Koshihikari. There were seven phenolic acids identified in leaves of Koshihikari including caffeic acid, vanillin, ferulic acid, sinapic acid, benzoic acid, ellagic acid, and cinamic acid, but only benzoic acid and ellagic acid were found in leaves of MNR2. In contrast, only vanillic acid and ellagic acid were observed in roots of Koshihikari, whilst ellagic acid and cinnamic acid were found in roots of MNR2. It was found that rice reduced amount of phenolic acids but promoted quantity of total phenolic content (TPC) and total flavonoid content (TFC) and level of antioxidant activity in chilling stress, although the level of responses varied between Japonica and Indica subtypes. Tolerant rice possessed greater bound flavonoids, phenolics and phenolic acids, but susceptible rice accumulated greater free TPC and TFC in reduced temperature. Findings of this study highlighted that phenolic constituents in bound forms of phenols, polyphenols, and flavonoids may play an active role in rice plants than phenolic acids under chilling stress but need further elaboration.
\end{abstract}

\section{Introduction}

Chilling stress is one among the major harmful abiotic stresses which limits growth of temperate plants. Low temperature (chilling) has negative impact on the survival, distribution, growth and reproduction of the plants [1]. The cold stress level is classified into chilling $\left(0-15^{\circ} \mathrm{C}\right)$ and freezing $\left(<0{ }^{\circ} \mathrm{C}\right)[2]$. The serious injury by chilling stress to plants is the induction of oxidative damages at cellular levels [3]. Rice is a temperate crop; therefore, low temperature alters its physiological process which leads to low production [4]. Rice is more sensitive to chilling stress than other crops such as wheat (Tiriticum aestivum L.) and barley (Hordeum vulgare L.), because the origin of this crop is in tropical and sub-tropical regions [2]. Low temperature causes physical damages to rice plants, such as weak germination percentage, low seedling vigor, high death rate and low spike fertility. It also results in the disorder in plant physiological processes, for instance, the changes in chlorophyll contents, lipid peroxidation, proline and other metabolites [5]. 
Cold stress increases phenolic contents and their constituents in plants cell wall such as suberin or lignin [6]. Flavonoids and lignin are the strong and potent antioxidants to function in rice as plants defenders [7]. The antioxidant activity of phenolic compounds plays a crucial role in neutralizing free radicals, triplet oxygen or decomposing peroxides [8]. However, to date, roles of phenolic compounds in rice against chilling stress have not been much known. The long-term shift and changes in environmental stresses and continued deterioration of cultivation lands are the serious threats to rice cultivation worldwide $[9,10]$. It is reported that exposing rice in the reproductive stage male sterility and sever yield lose [11]. Cold stress has been reported to cause severe reduction on growth and productivity of rice and affected rice distribution worldwide [12]. In 24 rice producing countries, major cultivating areas in China, Japan, and Korea which included about 15 million ha were under threat of low temperature stress which results in the loss of about 3.5 million tons annually [13-15]. Many rice varieties cannot be grown in approximately 7 million ha in Southeast and South Asia, due to the chilling stress $[2,16]$. Therefore, the breeding of rice tolerant to chilling stress is required for sustainable agriculture and food security in rice growing countries [13-17,18]. There were several quantitative trait loci (QTLs) involved in chilling stress have been isolated and cloned [19-21], however introduction of these genes into commercial rice has not been yet approached. The search for compounds in rice which involve in the mechanism of chilling mechanism might be more potential, because the application of these constituents on rice plants during either the vegetative or productive stages might be more promising.

To understand the responses of rice in chilling stress apparently helps to reduce harmful effects on rice seedlings occurred in low temperature. Therefore, this research was conducted to investigate the changes in phenolic constituents and antioxidant activity of between tolerant (Japonica subtype) and susceptible (Indica subtype) rice varieties in chilling stress condition.

\section{Materials and Methods}

Two rice varieties Koshihikari, and NMR2 were selected in this experiment. Of which Koshihikari (subtype: Japonica) seeds were purchased from Japan Agriculture, Higashi Hiroshima, Japan. NMR2 (subtype: Indica) seeds were kindly provided by Agricultural Genetics Institute, Vietnam. The seeds were soaked in $0.1 \%$ sodium hypochlorite $(\mathrm{NaOCl})$ for $30 \mathrm{~min}$. They were then washed with distilled water and sown in Petri dishes covered with the moist filter papers and placed at $30^{\circ} \mathrm{C}$ in an incubator for one week. The germinated seeds were sown in pots filled with commercial soil (JA-ZENCHU Co., Hiroshima, Japan) containing $0.16 \mathrm{~g}$ nitrogen $(\mathrm{N}), 0.2 \mathrm{~g}$ phosphorous $(\mathrm{P})$ and $0.26 \mathrm{~g}$ potassium $(\mathrm{K})$ in a greenhouse under optimal condition $\left(25 / 15{ }^{\circ} \mathrm{C}\right.$ day/night time, $14 \mathrm{~h}$ photoperiod) for one week. The experiment conducted based on Randomized Complete Block Design (RCBD) with four replications in a greenhouse and laboratory. Each bock (replication) consisted of four treatments ( 2 rice varieties and 2 temperature treatments).Thus; the experiment had totally 64 pots. The seedlings divided into two groups of control and treatment. The control group was maintained in the green house and the treatment group was chilled at $\left(5 / 4{ }^{\circ} \mathrm{C}\right.$ day/night $)$ as chilling stress in a chamber for one week. The samples were then collected to measure plant height and length. The dry weight of leaves and roots were measured after drying in an oven at $65^{\circ} \mathrm{C}$ for $72 \mathrm{hr}$ [22]. The samples then stored at $-20^{\circ} \mathrm{C}$ to identify and quantify phenolic compounds, and determine antioxidant activity.

\section{Extraction of Free Phenolics}

Free phenolic contents were measured following the method reported by Elzaawely et al., [23]. The amount of $0.3 \mathrm{~g}$ of leaves and $0.1 \mathrm{~g}$ of roots were extracted with 20, and $10 \mathrm{ml}$ Methanol (99.5\%), respectively. The mixture was placed on a stirrer machine and shaken for $4 \mathrm{~h}$. Then the mixture centrifuged (HITACHI, CF15RXII, Tokyo, Japan) at $15,000 \mathrm{rpm}$ for $10 \mathrm{~min}$ at $4{ }^{\circ} \mathrm{C}$ to collect the supernatants. The $\mathrm{pH}$ was adjusted to $1-2$. The solvent was evaporated by a rotary evaporator (SB350-EYELA, Tokyo, Japan) at $37{ }^{\circ} \mathrm{C}$. The precipitates were collected and mixed with methanol for further analysis. 


\section{Extraction of Bound Phenolics}

The residue of free phenolic extraction hydrolyzed with $20 \mathrm{ml}$ of $4 \mathrm{M} \mathrm{NaOH}$ at $50{ }^{\circ} \mathrm{C}$. Then, it was placed in the stirred machine for 4 hours. Thereupon, the mixture was centrifuged at 5,000 rpm for $10 \mathrm{~min}$ in room temperature. The mixture filtrated, and its $\mathrm{pH}$ was adjusted to 1.5 using concentrated $\mathrm{HCl}$. Then, it was extracted with ethyl acetate $99.5 \%$ three times. The supernatants of solvent were combined and dried by rotary evaporator at $30{ }^{\circ} \mathrm{C}$. The dried extract was reconstituted with methanol $99.8 \%$ and kept in a cold room at $4{ }^{\circ} \mathrm{C}$ for further measurement.

\section{Determination of Total Phenolic Content}

The content of total phenolic was measured following the Folin-Ciocalteu colorimetric method reported by $\mathrm{Ti}$ et al. [24]. Firstly, $0.125 \mathrm{ml}$ of the sample extracts and $0.5 \mathrm{ml}$ distilled water with $0.125 \mathrm{ml}$ of Folin-Ciocalteu's reagent $(10 \%)$ were added to test tube and mixed well. Thereupon, $1.25 \mathrm{ml} \mathrm{Na} 2 \mathrm{CO}_{3} 7.5 \%$ (w/v) with $0.5 \mathrm{ml}$ of distilled water was added to the mixture and kept in dark place for $30 \mathrm{~min}$. Finally, the absorbance was measured at $760 \mathrm{~nm}$ using spectrophotometer (DR/4000 U-HACH, Colorado, USA).

\section{Determination of DPPH Radical Scavenging Activity}

DPPH (2,2-Diphenyl-1-picrylhydrazyl) radical scavenging activity was measured following the method reported by Elzaawely et al. [23]. A $0.5 \mathrm{ml}$ of sample extract was mixed with $0.25 \mathrm{ml}$ of DPPH methanol solution and $0.5 \mathrm{ml}$ of $0.1 \mathrm{M}$ sodium acetate buffer (pH 5.5) and kept in a dark place for $30 \mathrm{~min}$. The absorbance was measured at $517 \mathrm{~nm}$ using a spectrophotometer (DR/4000 U-HACH, Colorado, USA). Radical scavenging activity was shown as the inhibition was calculated following the below formula:

$$
\text { DPPH Radical Scavenging Activity (\%) }=[(\text { Acontrol }- \text { Asample })] \times 100
$$

Where Acontrol was absorbance of reaction without a sample. Asample was the absorbance of the sample.

\section{Identification of Phenolic Compounds by HPLC}

The total phenolic contents were analyzed with HPLC machine according to Xuan et al. [25]. The HPLC (UV-2075-plus-JASCO, Tokyo, Japan) supplied with 2998 photodiode PDA, quaternary pump detectors, and a J-Pak Symphonia C18 column with dimensions of $4.6 \times 250 \mathrm{~mm}, 5 \mu \mathrm{m}$ (silica). The purified samples were filtered using a $0.22 \mu \mathrm{m}$ membrane filter and $5 \mu 1$ of the sample was injected into the HPLC machine. The mobile phase had two solvents, one (solution B) $0.1 \%$ of acetic acid and the other one (solution A) 100\% methanol. The phenolic contents were discovered at $254 \mathrm{~nm}$ with a flow rate of $1 \mathrm{ml}$ min- 1 using the following time gradient: 5\% A (0-5 minute); 20\% A (5-10 minute); 50\% A (10-20 minute); 80\% A (20-30 minute); 100\% A (30-40 minute); 100\% A (40-50 minute); $5 \%$ A (50-60 minute). The amount of $5 \mu 1$ the sample was used and replicated three times. The total phenolic contents were detected by comparing their retention times and quantified as the sample's peak areas compared with those of standards.

\section{Statistical Analysis}

The results are presented as (means \pm standard deviation). The data were analyzed with Minitab Minitab ${ }^{\circledR}$ 16.2.3 (2012 Minitab Inc., Philadelphia, USA) software using ANOVA. The significant differences were defined at $5 \%$ level.

\section{Results}

\section{Effects of Chilling Stress on Rice Growth}

Results in Table 1 indicated that the two varieties Koshihikari and MNR2 responded differently against temperature treatments. At $25 / 15^{\circ} \mathrm{C}$ (day/night), Koshihikari even obtained better elongation of shoots and roots, and dried weight of leaves and roots, the growth of MNR2 was less than that of 
Koshihikari. At $5 / 4{ }^{\circ} \mathrm{C}$ (day/night), the growth of both Koshihikari and MNR2 was stunt, however Koshihikari was less inhibited than MNR2 (Table 1). Significant difference was observed among treatments, and varieties (except for the root length). Findings of this experiment showed that Koshihikari (Japonica subtype) was more tolerant to chilling stress than MNR2 (Indica subtypef).

Table 1. Shoot and roots length, leaves and roots dry weight of seedlings subjected to chilling stress

\begin{tabular}{|c|c|c|c|c|c|}
\hline Variety & $\begin{array}{c}\text { Temperature } \\
\text { Treatment } \\
\left({ }^{\circ} \mathrm{C}\right)\end{array}$ & $\begin{array}{c}\text { Shoot } \\
\text { Height }(\mathrm{cm})\end{array}$ & $\begin{array}{l}\text { Root Length } \\
\text { (cm) }\end{array}$ & $\begin{array}{c}\text { Leaf Dry } \\
\text { Weight (g) }\end{array}$ & $\begin{array}{c}\text { Root Dry } \\
\text { Weight (g) }\end{array}$ \\
\hline \multirow{2}{*}{ Koshihikari } & $25 / 15$ & $40.0 \pm 0.9^{a}$ & $16.2 \pm 0.9^{\mathrm{a}}$ & $2.3 \pm 0.1^{\mathrm{a}}$ & $0.9 \pm 0.02^{\mathrm{a}}$ \\
\hline & $5 / 4$ & $34.3 \pm 1.1^{b}$ & $12.9 \pm 1.0^{\mathrm{b}}$ & $1.8 \pm 0.11^{\mathrm{b}}$ & $0.8 \pm 0.02^{\mathrm{a}}$ \\
\hline \multirow{2}{*}{ MNR2 } & $25 / 15$ & $29.3 \pm 0.5^{\mathrm{c}}$ & $14.1 \pm 0.8^{\mathrm{ab}}$ & $1.7 \pm 0.22^{\mathrm{bc}}$ & $0.7 \pm 0.04^{\mathrm{b}}$ \\
\hline & $5 / 4$ & $25.6 \pm 0.6^{\mathrm{d}}$ & $12.9 \pm 1.0^{\mathrm{b}}$ & $1.4 \pm 0.10^{\mathrm{c}}$ & $0.5 \pm 0.06^{\mathrm{c}}$ \\
\hline \multicolumn{6}{|c|}{ ANOVA } \\
\hline \multicolumn{2}{|c|}{ Variety } & $*$ & NS & $*$ & $*$ \\
\hline \multicolumn{2}{|c|}{ Treatment } & $*$ & $*$ & $*$ & $*$ \\
\hline \multicolumn{2}{|c|}{$\mathrm{V} \times \mathrm{T}$} & NS & NS & NS & NS \\
\hline
\end{tabular}

Means followed by different letters in a column are significantly different at $(p<0.05) . *$ indicates significant and NS, non-significant. Number

\section{Total Phenolic Contents (TPC)}

Table 2 showed that at the $25 / 15^{\circ} \mathrm{C}$ treatment, the tolerant Koshihikari principally had higher TPC than MNR2 in both leaves and roots. However, at the lower temperature $5 / 4{ }^{\circ} \mathrm{C}$, the susceptible MNR2 accumulated much higher TPC than the tolerant Koshihikari. Significant difference was observed among treatments and variety $\mathrm{x}$ treatment $(p<0.05)$. It was observed that in chilled condition, susceptible rice accumulated greater amount of TFC than the tolerant cultivar (Table 2).

Table 2. Responses of total phenolics to chilling stress in rice leaves and roots

\begin{tabular}{|c|c|c|c|c|c|}
\hline \multirow{2}{*}{ Variety } & \multirow{2}{*}{$\begin{array}{c}\text { Temperature } \\
\text { Treatment }\left({ }^{\circ} \mathbf{C}\right)\end{array}$} & \multicolumn{3}{|c|}{ Total Phenolics (mg GAE/g dry weight) } \\
\cline { 3 - 6 } & & \multicolumn{2}{|c|}{ Leaf } & \multicolumn{2}{c|}{ Root } \\
\cline { 3 - 6 } & & Free & Bound & Free & Bound \\
\hline \multirow{2}{*}{ Koshihikari } & $25 / 15$ & $19.7 \pm 2.1^{\mathrm{c}}$ & $64.7 \pm 12.7^{\mathrm{b}}$ & $12.9 \pm 1.8^{\mathrm{c}}$ & $53.5 \pm 5.3^{\mathrm{b}}$ \\
\cline { 2 - 6 } & $5 / 4$ & $29.1 \pm 1.9^{\mathrm{b}}$ & $95.8 \pm 1.5^{\mathrm{a}}$ & $14.1 \pm 1.5^{\mathrm{b}}$ & $101.1 \pm 6.2^{\mathrm{a}}$ \\
\hline \multirow{2}{*}{ MNR2 } & $25 / 15$ & $19.6 \pm 0.8^{\mathrm{c}}$ & $45.6 \pm 5.9^{\mathrm{c}}$ & $2.6 \pm 0.5^{\mathrm{d}}$ & $31.1 \pm 2.1^{\mathrm{c}}$ \\
\cline { 2 - 6 } & $5 / 4$ & $50.4 \pm 1.5^{\mathrm{a}}$ & $100.3 \pm 2.3^{\mathrm{a}}$ & $18.2 \pm 0.9^{\mathrm{a}}$ & $100.6 \pm 3.4^{\mathrm{a}}$ \\
\hline \multicolumn{2}{|c|}{ ANOVA } & $*$ & NS & NS & $*$ \\
\hline \multicolumn{2}{|c|}{ Variety } & $*$ & $*$ & $*$ & $*$ \\
\hline \multicolumn{2}{|c|}{ Treatment } & $*$ & $*$ & $*$ & $*$ \\
\hline \multicolumn{2}{|c|}{$\mathrm{V} \times \mathrm{T}$} & & & & \\
\hline
\end{tabular}

GAE: Gallic acid equivalent. Means followed by different letters in a column are significantly different at $(p<0.05)$ * indicates significant and NS, non-significant.

\section{Total Flavonoid Content (TFC)}

The value of TFC of leaves and roots of the two rice cultivars was illustrated in Table 3. It was found that the amount of TFC in rice leaves was greater than roots. In the $25 / 15^{\circ} \mathrm{C}$, TFC between the two cultivars Koshihikari and MNR2 was differed in bound form, but marked difference was observed between the two treatments. Significant difference was also found in the treatment $\mathrm{x}$ variety correlation (Table 2). 
Table 3. Responses of total flavonoid contents to chilling stress in leaves and roots

\begin{tabular}{|c|c|c|c|c|c|}
\hline \multirow{3}{*}{ Variety } & \multirow{3}{*}{$\begin{array}{c}\text { Temperature } \\
\text { Treatment }\left({ }^{\circ} \mathrm{C}\right)\end{array}$} & \multicolumn{4}{|c|}{ Total Flavonoid Content (mg RE/g dry weight) } \\
\hline & & \multicolumn{2}{|c|}{ Leaves } & \multicolumn{2}{|c|}{ Roots } \\
\hline & & Free & Bound & Free & Bound \\
\hline \multirow{2}{*}{ Koshihikari } & $25 / 15$ & $49.9 \pm 3.1^{\mathrm{b}}$ & $3.4 \pm 0.4^{\mathrm{d}}$ & $0.70 \pm 0.1^{\mathrm{b}}$ & $1.00 \pm 0.2^{\mathrm{b}}$ \\
\hline & $5 / 4$ & $90.4 \pm 1.6^{\mathrm{a}}$ & $6.3 \pm 0.6^{\mathrm{c}}$ & $1.07 \pm 0.3^{\mathrm{ab}}$ & $1.53 \pm 0.10^{\mathrm{a}}$ \\
\hline \multirow{2}{*}{ MNR2 } & $25 / 15$ & $54.7 \pm 10^{\mathrm{b}}$ & $4.3 \pm 1.0^{\mathrm{d}}$ & $0.79 \pm 0.1^{\mathrm{b}}$ & $0.80 \pm 0.2^{\mathrm{b}}$ \\
\hline & $5 / 4$ & $76.7 \pm 3.5^{\mathrm{a}}$ & $9.7 \pm 0.6^{\mathrm{c}}$ & $1.24 \pm 0.1^{\mathrm{ab}}$ & $3.14 \pm 0.2^{\mathrm{a}}$ \\
\hline \multicolumn{6}{|c|}{ ANOVA } \\
\hline \multicolumn{2}{|c|}{ Variety } & $*$ & NS & NS & $*$ \\
\hline \multicolumn{2}{|c|}{ Treatment } & $*$ & * & $*$ & $*$ \\
\hline \multicolumn{2}{|c|}{$\mathrm{V} \times \mathrm{T}$} & $*$ & $*$ & $*$ & $*$ \\
\hline
\end{tabular}

RE: Rutin equivalent. Means followed by different letters in a column are significantly different at $(p<0.05) .{ }^{*}$ indicates significant and NS, non-significant.

\section{Changes of Phenolic Acids in Rice Leaves and Roots}

Thirteen standard phenolic acids were examined to explore their presence in seedlings of Koshihikari and MNR2 varieties under control and chilling stress. The appearance and retention time of these compounds in the HPLC profile are shown in Figure 1.

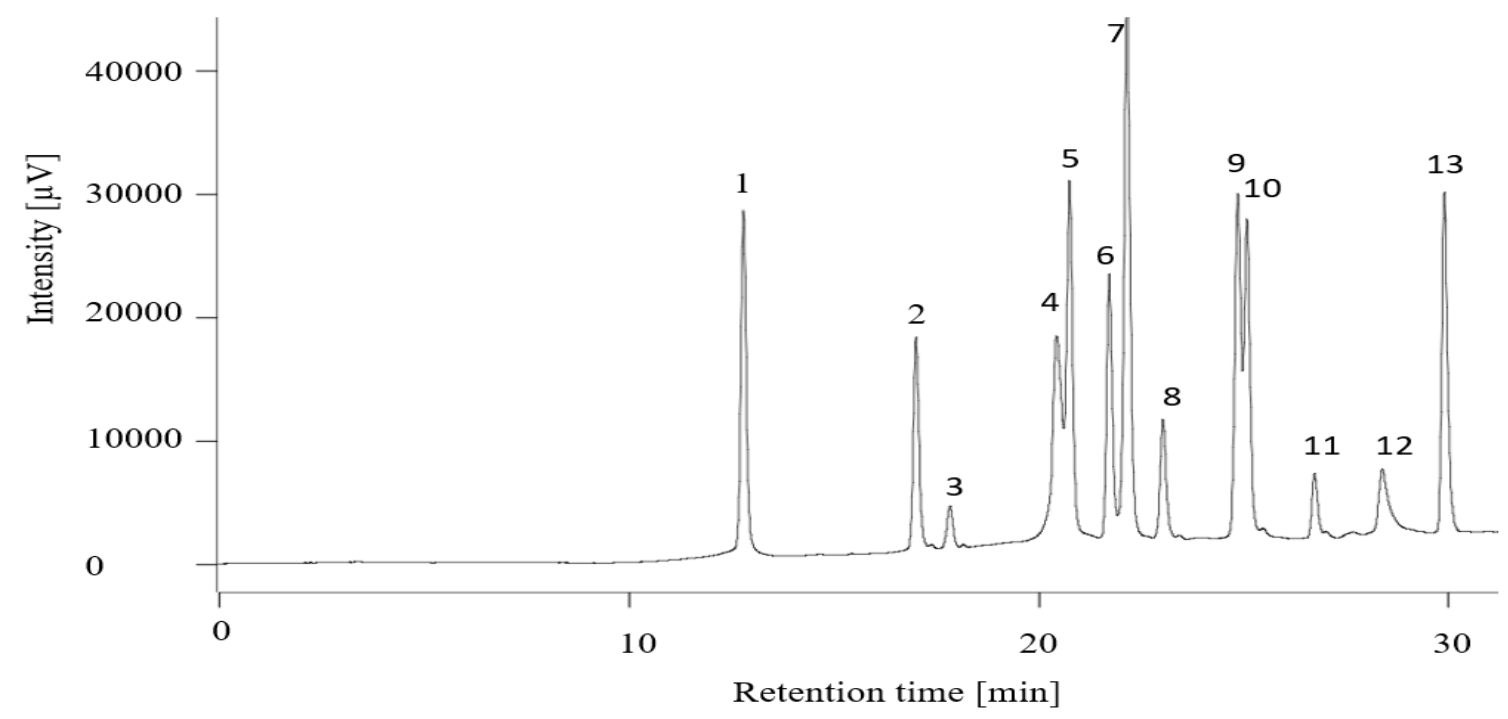

Figure 1. Phenolic acids detected by HPLC (at $254 \mathrm{~nm}$ ). 1. Gallic acid; 2. Protocatechuic acid;

3. Catechol; 4. Chlorogenic acid; 5. p-hydroxyl benzoic acid; 6. Vanillic acid; 7. Caffeic acid;

8. Vanillin; 9. Ferulic acid; 10. Sinapic acid; 11. Benzoic acid; 12. Ellagic acid; 13. Cinnamic acid

However, only seven phenolic constituents were detected in rice leaves (Table 3) whilst three compounds were observed in roots (Table 4). It was found that ellagic acid was present in both leaves and roots of Koshihikari and MNR2, whilst benzoic acid was found only in their leaves (Tables 3 and 4). 
Table 4. Phenolic constituents in rice leaves detected by HPLC

\begin{tabular}{|c|c|c|c|c|c|}
\hline \multirow{2}{*}{ Phenolic Acids } & \multirow{2}{*}{$\begin{array}{c}\text { Retention } \\
\text { Time (min) }\end{array}$} & \multicolumn{4}{|c|}{ Kariety } \\
\cline { 3 - 6 } & & $\mathbf{2 5 / 1 5}$ & $\mathbf{5 / 4}$ & $\mathbf{2 5 / 1 5}$ & $\mathbf{5 / 4}$ \\
\cline { 3 - 6 } & 24.48 & $4.02 \pm 1.19^{\mathrm{a}}$ & - & - & - \\
\hline Caffeic acid & 25.59 & $2.73 \pm 0.06^{\mathrm{b}}$ & $0.82 \pm 0.14^{\mathrm{d}}$ & - & - \\
\hline Vanillin & 25.76 & $0.62 \pm 0.03^{\mathrm{d}}$ & $0.31 \pm 0.05^{\mathrm{d}}$ & - & - \\
\hline Ferulic acid & 26.08 & $2.42 \pm 0.33^{\mathrm{b}}$ & $1.56 \pm 0.05^{\mathrm{c}}$ & - & - \\
\hline Sinapic acid & 27.60 & $2.60 \pm 8.71^{\mathrm{b}}$ & $1.23 \pm 0.01^{\mathrm{c}}$ & $1.40 \pm 0.05^{\mathrm{a}}$ & $1.45 \pm 0.04^{\mathrm{a}}$ \\
\hline Benzoic acid & 29.14 & $0.69 \pm 0.03^{\mathrm{d}}$ & $0.83 \pm 0.10^{\mathrm{d}}$ & $0.46 \pm 0.02^{\mathrm{b}}$ & $0.51 \pm 0.08^{\mathrm{b}}$ \\
\hline Ellagic acid & 30.12 & $6.42 \pm 6.87^{\mathrm{a}}$ & $2.68 \pm 0.62^{\mathrm{b}}$ & - & $0.45 \pm 0.02^{\mathrm{b}}$ \\
\hline Cinnamic acid & &
\end{tabular}

Means followed by different letters in columns of a variety are significantly different at $(p<0.05)$; $25 / 5$ and 5/4 are the treated day/night temperature; -: not detected

Table 5. Phenolic constituents in rice roots detected by HPLC

\begin{tabular}{|c|c|c|c|c|c|}
\hline \multirow{3}{*}{ Phenolic Acids } & \multirow{3}{*}{$\begin{array}{l}\text { Retention } \\
\text { Time (min) }\end{array}$} & \multicolumn{4}{|c|}{ Variety } \\
\hline & & \multicolumn{2}{|c|}{ Koshihikari } & \multicolumn{2}{|c|}{ MNR2 } \\
\hline & & $25 / 15$ & $5 / 4$ & $25 / 15$ & $5 / 4$ \\
\hline Caffeic acid & 24.48 & - & - & - & - \\
\hline Vanillin & 25.59 & $2.15 \pm 0.83^{\mathrm{a}}$ & - & - & - \\
\hline Ferulic acid & 25.76 & - & - & - & - \\
\hline Sinapic acid & 26.08 & - & - & - & - \\
\hline Benzoic acid & 27.60 & - & - & - & - \\
\hline Ellagic acid & 29.14 & $0.88 \pm 0.04^{\mathrm{b}}$ & $0.50 \pm 0.03^{\mathrm{c}}$ & $0.82 \pm 0.02^{\mathrm{a}}$ & $0.26 \pm 0.01^{b}$ \\
\hline Cinnamic acid & 30.12 & - & $0.24 \pm 0.00^{\mathrm{d}}$ & $0.76 \pm 0.01^{\mathrm{a}}$ & $0.21 \pm 0.01^{\mathrm{b}}$ \\
\hline
\end{tabular}

Means followed by different letters in columns of a variety are significantly different at $(p<0.05)$; $25 / 5$ and $5 / 4$ are the treated day/night temperature.

In general, more regarding to the contents of phenolic acids, in Koshihikari leaves, all compounds significantly reduced their quantities in the $5 / 4{ }^{\circ} \mathrm{C}$ as compared to those of the $25 / 15^{\circ} \mathrm{C}$ by two folds, except the amount of ellagic acid was increased, whilst caffeic acid was detected only in the $25 / 15^{\circ} \mathrm{C}$ treatment (Table 4). However, MNR2 possessed only ellagic acid and cinnamic acid which were detectable in the leaves, however their contents were not significantly different between the two treatments. In roots, ellagic acid was solely found in both Koshihikari and MNR2, whereas cinnamic acid was detected only in MNR2. Their quantities were also significantly reduced in the chilled condition as compared to that of the $25 / 15^{\circ} \mathrm{C}$ condition (Table 4). Findings in Table 3 and 4 highlighted that phenolic acids in leaves responded to the chilling stress were in a greater number than roots. Although the quantity of TFC in leaves and roots were almost similar, it was proposed that phenolic compounds other than phenolic acids may involve in the tolerant to chilling stress in

\section{Antioxidant Activity}

Figure 2 showed that the DPPH radical scavenging activity increased remarkably in leaves and roots of both Koshihikari and NMR in chilled treatment. At the control $25 / 5{ }^{\circ} \mathrm{C}$, the antioxidant activity of Koshihikari was significantly higher than NMR2, whereas insignificant difference was observed between their roots. In the treated $5 / 4{ }^{\circ} \mathrm{C}$, the DPPH radical scavenging activity in both leaves and roots of the two cultivars were markedly increased. The level of antioxidant activity in leaves was insignificant, whilst MNR2 exhibited remarkable greater capacity of the DPPH radical scavenging activity than that of Koshihikari (Figure 2). 

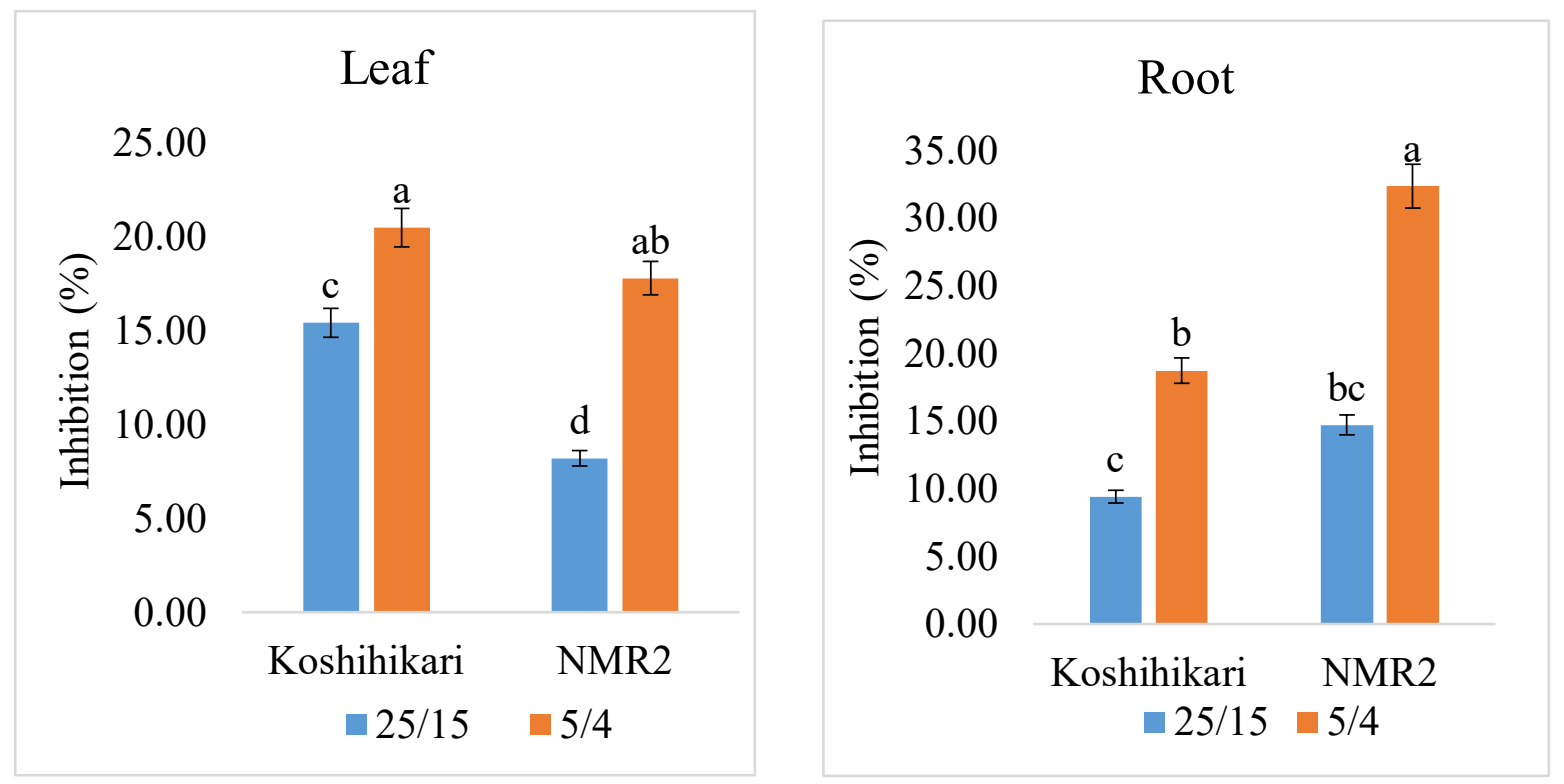

Figure 2. DPPH radical scavenging activity of Koshihikari and NMR2 in chilled stress. Values with similar letters are not significantly different $(p<0.05)$

\section{Discussion}

The findings of our study indicated that cold stress affected differentially the morphological traits, dry matter, phenolic contents and antioxidant activity of rice seedlings. Since the population is rapidly growing and urbanization is increasing, the expanding of rice production areas is facing difficulties. The spreading of rice cultivation is limited in colder areas because the high sensitivity of rice plant during vegetative and development stages against chilling stress. The results of this study revealed that chilled treatments inhibited growth of rice seedlings and declined rice biomass (Table 1). This observation has consisted with a previous study that cold stress might result in biomass reduction through limiting the water uptake by roots [1]. The tolerant Koshihikari revealed greater plant height, root length and dry matter in chilled treatment rather than NMR2 (Table 1).

The increase of higher radical scavenging activity in both Koshihikari and NMR2 might associate with the accelerated level of total phenolic contents (Table 2, Figure 2). Total phenolic content (TFC) were strongly accelerated in both rice cultivars (Table 2). In this study, the TFC in rice leaves and roots under chilling stress was higher as compared to the TFC in a previous study under water deficit stress [26]. The TFC included both free and bound form in leaves and roots was associated with the reduced temperature (Table 2). Findings of this study were similar with previous reports which noticed that abiotic stress induced the synthesis of phenolic compounds in plant tissue [27-29]. In contrast, Posmyk et al. [30] concluded that phenolic contents decreased dramatically in soybean seedlings during exposure to cold stress. The determination of phenolic contents in response to stress may help to explore the tolerant mechanism of crops, thus helped to prevent from loss of crop production. In this study, seven phenolic constituents were found in rice leaves, whilst only three phenolic acids were detected in rice roots to exhibit that phenolic acids in rice leaves responded to chilled stress than roots (Tables 3,4). Phenolic compounds play the role as antioxidants and induce the enzymatic antioxidant system in the cell during the stress [31,32]. In our findings, the presence and amounts of phenolic acids responded differentially under chilling stress. However, whilst the DPPH radical scavenging activity and TFC were significantly promoted, the quantity and presence of phenolic acids were reduced to indicate that phenolic compounds other than phenolic acids might be involved in the tolerance to chilling stress in rice. Further studies are needed to explore the presence and involvement of other phenolic compounds other than phenolic acids such as phenols, polyphenols, and flavonoids in cold treatments.

Reactive oxygen species (ROS) including superoxide $\left(\mathrm{O}_{2}\right)$, the hydroxyl radical (HO-) which are produced at low levels as normal byproducts of plant cellular metabolism, mainly in organelles 
such as chloroplast, mitochondria. However the abiotic stresses lead to excessive production of ROS that then react with DNA, lipid and protein to cause cellular oxidative damage [33,34,]. It is already known that (ROS) is induced through chilling stress to cause a series of deleterious process, such degradation of protein, lipid peroxidation and nucleic acids in the cell [35]. The antioxidant activity of rice leaves and roots in this study were measured using the method of DPPH assay (Figure 2), thus the changes of other antioxidant capacities such as ABTS and reducing power should also be surveyed, as they were reported to be associated with abiotic stresses from submergence [36] and drought [37]. Secondary metabolites such as momilactones A and B were reported to be involved in drought and salinity tolerance in rice [38], but their roles against chilling stress should be further elaborate.

\section{Conclusion}

Findings of this study revealed that the responses of secondary metabolites including flavonoids and phenolics, and antioxidant activity between tolerant and susceptible rice in chilling stress were differed between Japonica and Indica subtypes. The antioxidant levels were strongly accelerated in $5 / 4{ }^{\circ} \mathrm{C}$ as compared to that of the $25 / 15^{\circ} \mathrm{C}$ treatment, however roots of the susceptible rice increased the highest DPPH scavenging activity. Although there was greater number of phenolic acids in leaves involved in the tolerant potential than roots, rice significantly reduced quantity of phenolic acids in chilled condition, whereas total phenolic contents and total flavonoid content were in contrast strongly promoted. This study showed that the DPPH radical scavenging and bound forms of phenols, polyphenols, and flavonoids may associate with the tolerance of rice to chilling stress rather than their free form, although phenolic acids may not be much involved.

\section{Conflict of Interest}

The authors declare no conflict of interests.

\section{Acknowledgment}

The authors thank Japan International Cooperation Agency (JICA) for providing scholarships to Naqib Ahmad Fkoori and Ramin Rayee. Thanks are also due to Nguyen Tat Thanh University, Vietnam, for their partial support to this research.

\section{References}

[1] A. Aghaee, et al., Physiological responses of two rice (Oryza sativa L.) genotypes to chilling stress at seedling stage, African Journal of Biotechnology. 10(39) (2011) 7617-7621.

[2] Q. Zhang, et al., Rice and cold stress: methods for its evaluation and summary of cold tolerancerelated quantitative trait loci, Rice. 7(1) (2014) 1-12.

[3] S. C. Xu, et al., Responses of antioxidant enzymes to chilling stress in tobacco seedlings, Agricultural Science in China. 9(11) (2010) 1594-1601.

[4] S. Zhang, et al., Sex-related differences in morphological, physiological, and ultrastructural responses of Populus cathayana to chilling, Journal of Experimental Botany. 62(2) (2010) 675686.

[5] Z. Liu, et al., Water strategy of mycorrhizal rice at low temperature through the regulation of PIP aquaporins with the involvement of trehalose, Applied Soil Ecology. 84 (2014) 185-191.

[6] A. Ramakrishna, G. A. Ravishankar, Influence of abiotic stress signals on secondary metabolites in plants, Plant Signal Behaviour. 6(11) (2011) 1720-1731.

[7] Y. Sakihama, et al., Plant phenolic antioxidant and prooxidant activities: phenolics-induced oxidative damage mediated by metals in plants, Toxicology. 177(1) (2002) 67-80. 
[8] J.C. Pennycooke, S. Cox, C. Stushnoff, Relationship of cold acclimation, total phenolic content and antioxidant capacity with chilling tolerance in petunia (Petunia $\mathrm{x}$ hybrid), Environmental and Experimental Botany. 53(2) (2005) 225-232.

[9] N.E. Korres, et al., Temperature and drought impacts on rice production: An agronomic perspective regarding short-and long-term adaptation measures, Water Resources and Rural Development. (9) (2017) 12-27.

[10] L.M. Raboin, et al., Upland rice varieties for smallholder farming in the cold conditions in Madagascar's tropical highlands, Field Crops Research. (169) (2014) 11-20.

[11] J. Suh, et al., Identification and analysis of QTLs controlling cold tolerance at reproductive stage and validation of effective QTLs in cold-tolerant genotypes of rice (Oryza sativa. L), Theory Applied Genetic. 120(5) (2010) 985-995.

[12] G. Xie, H. Kato, R. Imai, Biochemical identification of the OsMKK6-OsMPK3 signaling pathway for chilling stress tolerance in rice, Biochemical Journal. 443(1) (2012) 95-102.

[13] Y.W. Zeng, et al., QTLs of cold tolerance-related traits at the booting stage for NIL-RILs in rice revealed by SSR, Genes Genomics. 31(2) (2009) 143-154.

[14] Q.J. Lou, et al., A major QTL associated with cold tolerance at seedling stage in rice (Oryza sativa L.), Euphytica. 158(2) (2007) 87-94.

[15] K.K. Jena, et al., Identification of cold-tolerant breeding lines by quantitative trait loci associated with cold tolerance in rice, Crop Science. 52(2) (2012) 517-523.

[16] F.X. Liu, et al., Identification and mapping of quantitative trait loci controlling cold-tolerance of Chinese common wild rice (O. rufipogon Griff.) at booting to flowering stages, Chinese Science Bulletin. 48(19 (2003) 2068-2071.

[17] C. Ye, et al., Cold tolerance in rice varieties at different growth stages, Crop and Pasture Science. 60(4) (2009) 328-338.

[18] V.C. Andaya, D.J. Mackill, Mapping of QTLs associated with cold tolerance during the vegetative stage in rice, Journal of Experimental Botany. 54(392) (2003) 2579-2585.

[19] H.H. Hu, et al., Characterization of transcription factor gene SNAC2 conferring cold and salt tolerance in rice, Plant Molecular Biology. 67(2) (2008) 169-181.

[20] V.C. Andaya, T.H. Tai, Fine mapping of the qCTS12 locus, a major QTL for seedling cold tolerance in rice, Theoritical and Applied Genetic. 113(3) (2006) 467-475.

[21] Z. Sun, et al., Near-isogenic lines of Japonica rice revealed new QTLs for cold tolerance at booting stage, Agronomy. 9(1) (2019) 40.

[22] E. Landolt, The family of Lemnaceae. A monographic study. (Vero"ff. Geobot. Inst. ETH, Zurich), 1987; Vol. 2

[23] A.A. Elzaawely, T. D. Xuan, S. Tawata, Essential oils, kava pyrones and phenolic compounds from leaves and rhizomes of Alpinia zerumbet (Pers.) B.L. Burtt. \& R.M. Sm. and their antioxidant activity, Food Chemistry. 103(2) (2007) 486-494.

[24] H. Ti, et al., Dynamic changes in the free and bound phenolic compounds and antioxidant activity of brown rice at different germination stages, Food Chemistry. 161 (2014) 337-344.

[25] T.D. Xuan, et al., Correlation between growth inhibitory exhibition and suspected allelochemicals (phenolic compounds) in the extract of alfalfa (Medicago sativa L.), Plant Production Science. 6(3) (2003) 165-171.

[26] R. Rayee, et al., Imposed water deficit after anthesis for the improvement of macronutrients, quality, phytochemicals, and antioxidants in rice grain, Sustainability 10(12) (2018) 4843. 
[27] R.A. Dixon, et al., The phenylpropanoid pathway and plant defence-a genomics perspective, Molecular Plant Pathology. 3(5) 2002 371-390.

[28] S.Weidner, et al., Phenolic compounds and properties of antioxidants in grapevine roots [Vitis vinifera L.] under drought stress followed by recovery, Acta Societatis Botanicorum Poloniae. 78(2) (2009) 97-103.

[29] S. Swigonska, et al., Influence of abiotic stress during soybean germination followed by recovery on the phenolic compounds of radicles and their antioxidant capacity, Acta Societatis Botanicorum Poloniae. 83(3) (2014) 209-218.

[30] M.M. Posmyk, et al., Antioxidant enzymes and isoflavonoids in chilled soybean (Glycine max L.) Merr.) seedlings, Journal of Plant Physiology. 162(4) (2005) 403-412.

[31] M.K. Zainol, et al., Antioxidative activity and total phenolic compounds of leaf, root and petiole of four accessions of Centella asiatica (L.), Urban Food Chemistry. 81(4) (2003) 575-581.

[32] M.M. Oh, H.N. Trick, C.B. Rajashekar, Secondary metabolism and antioxidants are involved in environmental adaptation and stress tolerance in lettuce, Journal of Plant Physiology. 166(2) (2009) 180-191.

[33] D. Mittal, DA. Madhyastha, A. Grover, Genome-wide transcriptional profiles during temperature and oxidative stress reveal coordinated expression patterns and overlapping regulations in rice, Plos One. 7(7) (2012) e40899.

[34] N. Murata, The mechanism of photoinhibition in vivo: Revaluation of the roles of catalase, tocopherol, non-photochemical quenching, and electron transport, Biochimica et Biophysica Acta. 1817(8) (2012) 1127-1133.

[35] I. Fridovich, The biology of oxygen radicals, Science. 201(4359) (1978) 875-880.

[36] T.D. Xuan, D.T. Khang, Effects of exogenous application of protocatechuic acid and vanillic acid to chlorophylls, phenolics and antioxidant enzymes of rice (Oryza sativa L.) in submergence, Molecules. 23(3) (2018) 620.

[37] N.T. Quan, et al., Involvement of secondary metabolites in response to drought stress of rice (Oryza sativa L.), Agriculture. 6(2) (2016) 23.

[38] T.D.Xuan, et al., Allelopathic momilactones A and B are implied in rice drought and salinity tolerance, not weed resistance. Agronomy for Sustainable Development. 36(3) (2016) 52. 